\title{
SiM
}

\section{Patch-Burn Grazing Effects on Cattle Performance: Research Conducted in a Working Landscape}

\author{
By Stephen L. Winter, Samuel D. Fuhlendorf, and Mark Goes
}

\section{On the Ground}

- Patch-burn grazing is a range management strategy that might be able to simultaneously optimize livestock production objectives and wildlife habitat objectives.

- We compared patch-burn grazing to a traditional range management strategy in multiple pastures, representing a variety of land ownership and management histories, dispersed across a relatively large geographic area. Our results likely represent what land managers could expect if they adopted patch-burn grazing in similar situations.

- We found that cattle performance in pastures managed with patch-burn grazing did not differ from that found in pastures managed with a traditional range management strategy. This suggests that land managers who adopt patch-burn grazing in our study region might be able to maintain levels of cattle performance they are accustomed to. Simultaneously, they might also be able to achieve wildlife habitat objectives that might not have been possible with the application of traditional range management strategies.

- More research and trials of patch-burn grazing in other regions and vegetation types will further help land mangers determine if patch-burn grazing is a range management strategy that could be useful when applied to their unique circumstances.

Keywords: livestock production, range management, wildlife habitat.

Rangelands 36(3):2-7

doi: 10.2111/Rangelands-D-13-00079.1

(c) 2014 The Society for Range Management

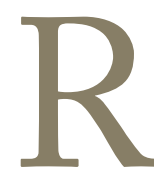

ange mangers have traditionally sought to manipulate the distribution of grazing animals so that moderate levels of grazing animal impacts on vegetation, soil, and water resources are evenly distributed across management units. ${ }^{1,2}$ In contrast to traditional range management practices, patch-burn grazing uses fire to concentrate grazing animals, and their associated impacts, on vegetation, soil, and water resources, in a portion (patch) of a management unit that has recently burned. ${ }^{3}$ With patchburn grazing, other patches within the same management unit that have not recently burned experience reduced levels of grazing animal activity and impact corresponding to the length of time since the last occurrence of fire. The contrasting levels of grazing animal impact within the management unit can generate patches of vegetation that differ markedly in plant species composition and structure (Fig. 1).

Whereas the traditional model of range management (even distribution of moderate animal impact) might optimize sustainable livestock production objectives, it might not be sufficient for the maintenance of plants and animals that require habitat conditions different from those created by moderate grazing animal impact, i.e., species whose habitat needs are best provided by heavily- or lightly-impacted rangelands. ${ }^{4-6}$ Additionally, some rangeland wildlife species require markedly different habitats at different times during their life cycle. If entire landscapes are managed with similarly moderate levels of grazing animal impact, evenly distributed across all management units within the landscape, such landscapes might not provide sufficient habitat for all portions of those species' requirements.

The ability of rangelands to provide habitat for wildlife and enhance biodiversity values will often depend on the ability of land managers to simultaneously optimize objectives associated with those values and objectives associated with livestock production. Additionally, integrating fire into range management is warranted for livestock production, bio- 


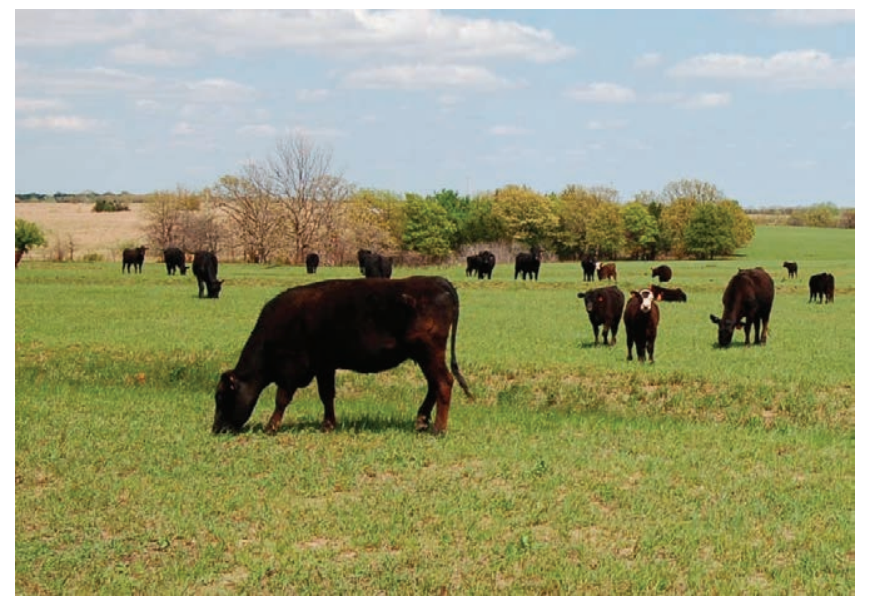

Figure 1. A cow-calf herd in a patch-burn grazing pasture. Contrast the vegetation in the recently burned patch where the cattle are grazing (patch-burned in February, photo taken in April of the same year) with the vegetation patch in the upper left of the photo that had not been burned in at least a year.

diversity, and ecosystem maintenance purposes. ${ }^{6}$ Although patch-burn grazing has previously been shown to result in animal performance that is equal or superior to that resulting from traditional range management practices, those results are from a limited number of studies. ${ }^{7-9}$ Widespread adoption of patch-burn grazing on lands where livestock production is a primary objective will in part require a substantial body of evidence assuring livestock producers that livestock production will not be compromised by its adoption. Furthermore, this body of evidence will need to be generated from a variety of locations and vegetation types in order for its general applicability to be considered reliable. ${ }^{10}$ Finally, although results of a management practice such as patch-burn grazing might be evident in a highly controlled research setting, in order for it to be adopted by private livestock producers those results must also be evident when the management practice is applied to working landscapes such as ranches.

\section{A Research Opportunity in a Working Landscape}

We assessed the effects of patch-burn grazing on cattle performance as part of a larger study examining the influence of patch-burn grazing on several variables representing livestock and biodiversity values. ${ }^{11} \mathrm{We}$ worked in multiple pastures, representing a variety of land ownership and management histories, dispersed across a relatively large geographic area (four counties). Some pastures were owned by the same individuals or families that managed the cattle herds utilizing those pastures, some pastures were owned by absentee landowners and were grazed by cattle owned and managed by local livestock producers, and some pastures were located on Wildlife Management Areas owned by the state of Nebraska but grazed by cattle owned and managed by local livestock producers. The private lands pastures had a long history of being used for cattle grazing, whereas pastures in the Wild- life Management Areas had a varied history of being hayed, burned, or rested.

The private landowners in our study largely represented individuals with an interest in range management practices that could simultaneously maintain or enhance range condition, livestock productivity, and wildlife habitat objectives. Many of these individuals had previously participated in habitat restoration projects, such as tree clearing and prescribed burning, that were cost-shared by the Nebraska Game and Parks Commission (NG\&PC) and the Northern Prairies Land Trust (NPLT). All private landowners whose pastures were included in this study entered into contracts that specified cattle stocking rates and prescribed burning schedules in exchange of further cost-share funds. During our study, all prescribed burning at our study sites was conducted by the livestock producers and land managers responsible for each site. Because our study sites were owned and managed by different individuals or organizations, we were unable to conduct our research in a manner comparable to what is possible in well-controlled studies utilizing long-established research pastures. Regardless, our results are informative because our study likely approximated conditions that would be experienced by other landowners and livestock producers who are considering patch-burn grazing on lands they own and manage.

\section{Study Sites and Study Design}

Our study sites were characterized by tallgrass prairie or, in some instances, areas that had previously been cropland but had long since been planted to or recolonized by native grasses and forbs characteristic of tallgrass prairie. Predominant grasses included big bluestem (Andropogon gerardii Vitman), little bluestem (Schizachyrium scoparium [Michx.] Nash), Indiangrass (Sorghastrum nutans [L.] Nash), smooth brome (Bromus inermis Leyss.), and Kentucky bluegrass (Poa pratensis L.). Our study pastures ranged in size from 72-168 acres (average, 103 acres). In the six pastures that were managed with patch-burn grazing (hereafter PBG pastures), approximately one-third of each pasture was burned in the spring of each successive year of our 3-year study (2009-2011; Fig. 2). In the seven pastures managed in a traditional manner that strives to evenly distribute grazing animals across the management unit (hereafter TRAD pastures), the entire pasture was burned in the spring during the first year of the study (2009) but was not burned in subsequent years (2010 and 2011).

We sought to stock all PBG and TRAD pastures at a moderate stocking rate throughout the duration of our study (see online supplemental material at http://dx.doi.org/10.2111/ RANGELANDS-D-13-00079.s1). Prior to the first grazing season (2009), stocking rates were determined using USDA Natural Resources Conservation Service estimates of forage productivity (1,500-5,000 pounds/acre) for the major soil types of each pasture and productivity estimates were adjusted downward to account for the presence of woodlands where forage was presumably limited. Our study pastures were stocked with cow-calf herds (with a bull present during 


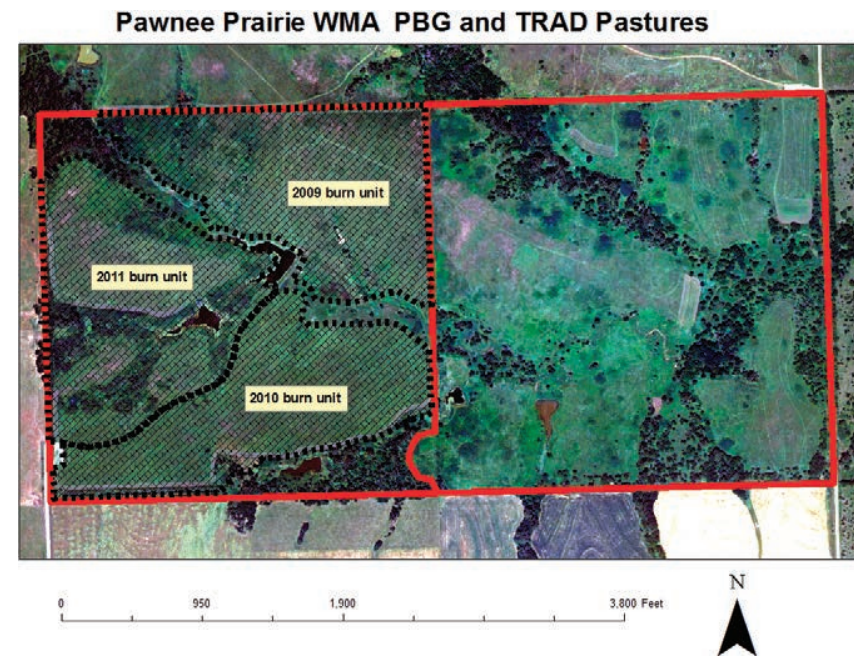

Figure 2. A southeastern Nebraska study site consisting of a patch-burn grazing pasture (PBG; pasture on the left) next to to a traditionally managed pasture (TRAD; pasture on the right). Spring-prescribed fires were conducted in three separate patches in 3 consecutive years (2009, 2010, and 2011) in the PBG pasture. In the TRAD pasture, a single spring prescribed fire was conducted across the entire pasture in 2009 and no prescribed fires were conducted in 2010 or 2011.

at least a portion of each grazing season) from approximately 10 April to 10 October in 2009, and approximately 10 May to 10 October in 2010 and 2011 (Fig. 3).

During each year of the study, we assessed cattle body condition score (BCS) for each cow in each pasture once in the spring and once in the early fall. One site of paired pastures (i.e., a PBG and a TRAD pasture that were adjacent to each other) served as a field classroom for a community college Animal Science program, and a portable scale was available to measure animal body mass. At this site, we measured cow body mass in the spring and again in the fall of each year, whereas calf body mass was only measured in the fall of each year. Full treatment of study sites and methods is available in the online supplemental material accompanying this article (available at http://dx.doi.org/10.2111/ RANGELANDS-D-13-00079.s1).

\section{What We Found}

Averaged across all years of our study, BCS of cows turned out in PBG pastures in the spring was statistically similar to that of cows turned out in TRAD pastures, assuring that endof-season BCS scores would not reflect differences in BCS that might have existed at the start of the grazing season (see online supplemental material at http://dx.doi.org/10.2111/ RANGELANDS-D-13-00079.s1 for full treatment of statistical analyses and results). When we averaged BCS scores across all the years of our study, end-of-season cow BCS in the PBG pastures was not statistically different from that in the TRAD pastures (Fig. 4). At the pair of pastures where a portable scale was available to measure cow and calf body mass, cow body mass at the start of the grazing season, averaged across all years of the study, did not differ between the PBG pasture and

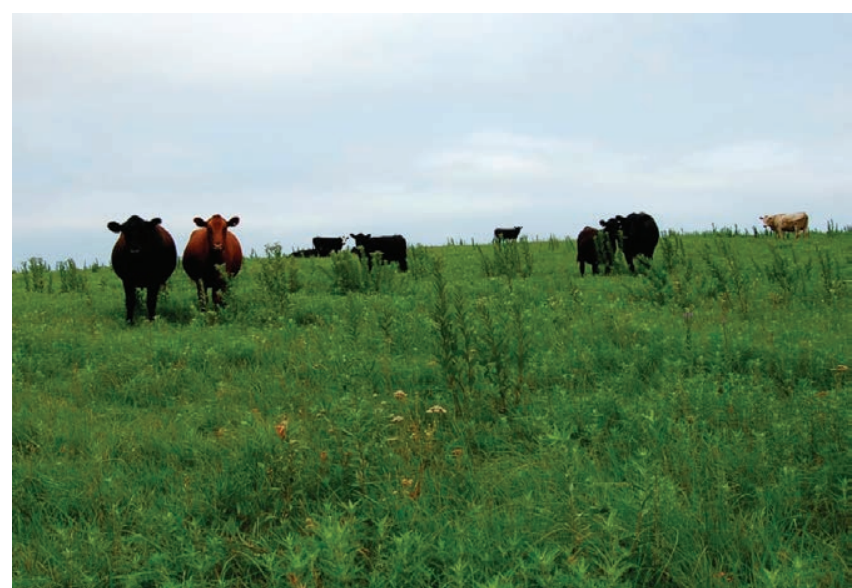

Figure 3. A cow-calf herd in one of the patch-burn grazing pastures used in our southeastern Nebraska study. This photo was taken in July and these animals are located in a patch that was burned in April of the same year.

the TRAD pasture. Body mass of cows in the PBG pasture at the end of the grazing season, averaged across all years of the study, was statistically similar to body mass of cows in the TRAD pasture (Fig. 5). Calf body mass was only measured at the end of each grazing season, and for this measure of animal performance, results were similar to the other measures; averaged across all years of the study, calf body mass at the end of the grazing season did not statistically differ between the PBG pasture and the TRAD pasture (Fig. 6).

\section{Implications of Our Research}

Following fire, forage regrowth can be of high quality and this can have a profound influence on grazing animal distribution, as has been documented around the globe with multiple herbivores. ${ }^{12}$ With patch-burn grazing, cattle and bison in the Great Plains of North America spend 31-75\% of their time within the most recently burned patches of a management unit. ${ }^{7,9,13}$ We compared two range management practices that both incorporated the use of fire but likely had markedly different effects on cattle distribution. In spite of this, we found no differences in cattle performance between the two practices. The patch-burn grazing practice involved the patchy distribution of fire in pastures such that a recently-burned patch occurred within a different portion of each pasture during each of 3 years. Cattle distribution within our PBG pastures was likely concentrated in different patches in different years, with the greatest cattle grazing activity likely occurring in the most recently burned patch. The traditional range management practice applied to the TRAD pastures in our study consisted of the application of fire across the entire pasture only in the first year of our 3-year study. Cattle grazing activity in our TRAD pastures was likely distributed more evenly across each pasture during each year of our study.

Because our measures of cattle performance did not differ between PBG and TRAD pastures, we surmise that cattle within all pastures had access to, and were able to effective- 


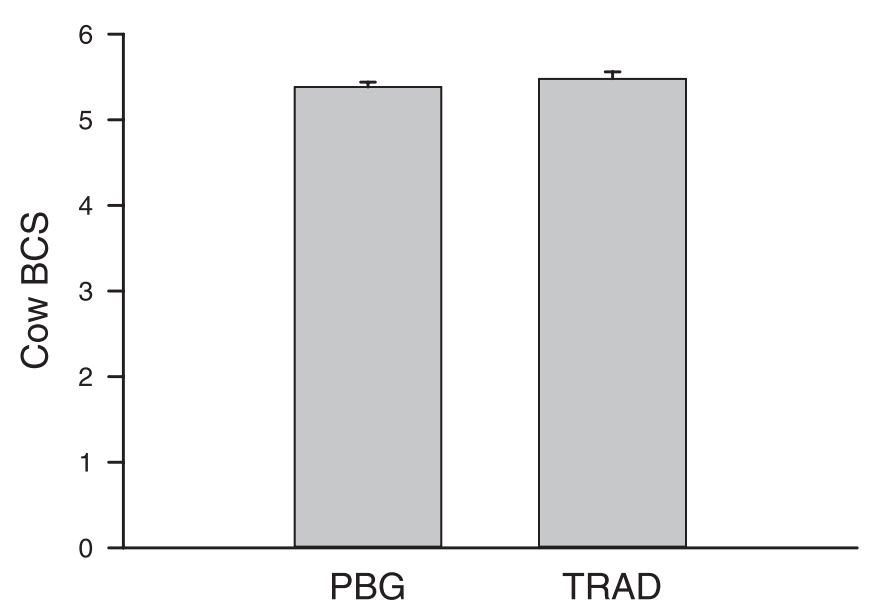

Figure 4. Average body condition score (BCS; error bars represent standard errors), averaged across 3 years of study (2009-2011), of cows at the end of the grazing season in six patch-burn grazing pastures (PBG) and seven pastures managed with a traditional range management practice (TRAD) in southeastern Nebraska.

ly utilize, equal levels of high-quality forage. The PBG and TRAD pastures presumably differed in where high-quality forages were located within a pasture. Within PBG pastures, high-quality forage was likely concentrated within the most recently burned patch. ${ }^{12}$ In the TRAD pastures, high-quality forage was likely more evenly distributed across each pasture as a result of the burn that occurred across the entirety of those pastures in 2009, the first year of the study. ${ }^{14}$ In subsequent years of the study (2010-2011), high-quality forage in the TRAD pastures was likely located in grazing patches that had been established during the first year of the study, ${ }^{14}$ but we surmise these grazing patches were still distributed relatively evenly across each TRAD pasture. Ultimately, the similarity of cattle performance between PBG and TRADF is probably best explained by the similarity of stocking rates across all pastures of our study, because stocking rate has repeatedly been shown to have an overriding influence on animal performance. ${ }^{15,16}$ Additionally, stocking rate would likely play a role in whether or not patch-burn grazing results in a mosaic of patches with contrasting vegetation structure in a management unit. Conceivably, if stocking rates are too high, a corresponding high level of cattle foraging would occur outside of the recently burned patch. This could result in patches that haven't recently burned being characterized by vegetation structure that is more similar to that found in a recently burned patch.

Cattle performance with patch-burn grazing has been previously reported from a limited number of locations; two in Oklahoma and one in Colorado. ${ }^{7-9}$ At one of the Oklahoma locations, a tallgrass prairie in the northeast part of the state, neither yearling weight gain nor cow BCS differed between patch-burn grazing pastures and traditionally managed pastures during 4 (yearling weight gain) and 5 (cow BCS) years of study. At the other Oklahoma location, a mixed-grass prairie in the southwestern part of the state, yearling weight gain was found to be superior in patch-burn grazing pastures

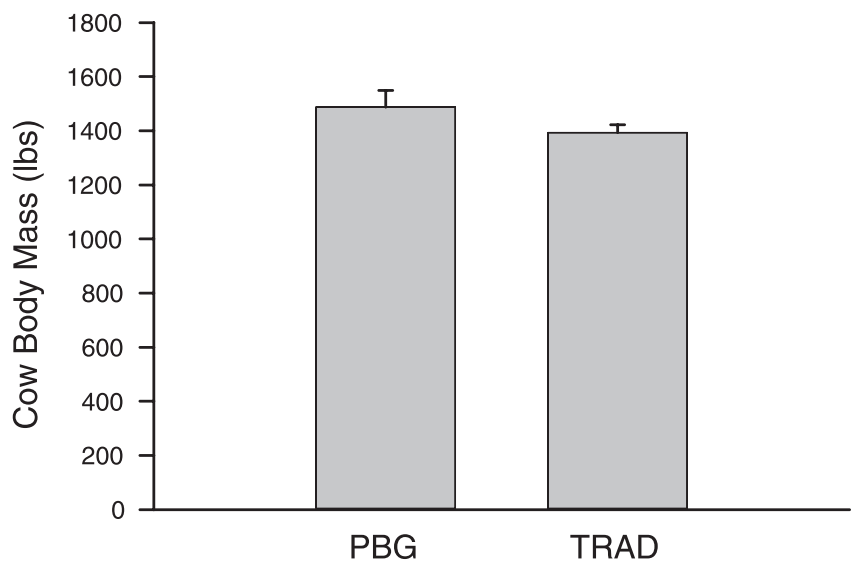

Figure 5. Average body mass (pounds; error bars represent standard errors), averaged across 3 years of study (2009-2011), of cows at the end of the grazing season in one patch-burn grazing pasture (PBG) and one pasture managed with a traditional range management practice (TRAD) in southeastern Nebraska.

compared to traditionally managed pastures after 11 years of study. During 4 years of study at the Colorado study site, yearling weight gain in patch-burn grazing pastures was not different from that found in traditionally managed pastures during 3 years. In 1 year of the 4-year study at the Colorado study site, yearling weight gain in patch-burn grazing pastures was superior to that in traditionally-managed pastures.

At the Oklahoma tallgrass prairie study site, traditionally managed pastures were similar to the TRAD pastures in our study in that each pasture was burned in its entirety once every 3 years. The research in Oklahoma tallgrass prairie, however, differed from ours in Nebraska tallgrass prairie in that the Oklahoma patch-burn grazing pastures consisted of six patches with one patch burned in the spring and another patch burned in the summer during each successive year. The PBG pastures in our Nebraska study consisted only of three patches burned in successive springs. At the Oklahoma mixed-grass prairie study site, traditionally managed pastures were never burned, whereas the patch-burn grazing pastures consisted of four patches burned in successive springs. At the Colorado shortgrass prairie study site, the patch-burn grazing pastures also consisted of four patches, but patches were burned in the fall of successive years. Traditionally managed pastures in the Colorado site were not burned.

Patch-burn grazing is similar to many commonly-practiced forms of rotational grazing ${ }^{16}$ in that animal distribution is manipulated so that vegetation patches within a landscape experience a period of high animal impact, followed by a period of rest. However, with common forms of rotational grazing, the period of rest is usually represented by a complete exclusion of grazing livestock, rest periods are often shorter than those occurring with patch-burn grazing, and regulation of animal distribution requires high levels of management input, infrastructure, and labor (fences, water, herding). Finally, common forms of rotational grazing differ from patch-burn 


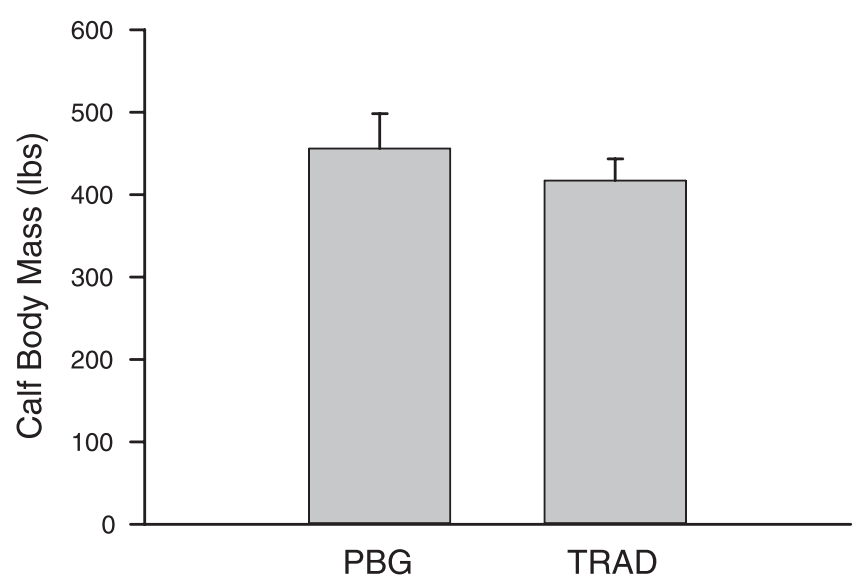

Figure 6. Average body mass (pounds; error bars represent standard errors), averaged across 3 years of study (2009-2011), of calves at the end of the grazing season in one patch-burn grazing pasture (PBG) and one pasture managed with a traditional range management practice (TRAD) in southeastern Nebraska.

grazing with regards to fundamental principles of grazing animal ecology. With common forms of rotational grazing, a livestock manager uses fencing to override the selective preferences of grazing animals, forcing them to forage in areas where they otherwise wouldn't forage, resulting in decreased individual animal performance. With patch-burn grazing, grazing animals are allowed to selectively forage within landscapes, providing them with the opportunity to maximize individual animal performance.

Patch-burn grazing has great promise for manipulating and enhancing wildlife habitat on rangelands. ${ }^{3}$ For instance, a comparison of patch-burn grazing pastures and traditionally managed pastures in Oklahoma tallgrass prairie found that bird communities in patch-burn grazing pastures were more diverse. ${ }^{17}$ Some bird species, such as Henslow's sparrow (Fig. 7), were only found in the Oklahoma patch-burn grazing pastures because they required habitat conditions that were not present in the traditionally managed pastures. This species was also present at some of our study sites ${ }^{11}$ and it remains to be seen if this species responds to patch-burn grazing in southeastern Nebraska in a manner similar to what was found in Oklahoma.

Furthermore, patch-burn grazing represents a way to integrate fire into range management without creating a conflict between the provision of sufficient fuel for fires and sufficient forage for livestock. However, the degree to which patch-burn grazing, or any other management strategy, might be adopted on a widespread basis could depend in large part on the level of livestock production resulting from its implementation. Our results were similar to those of other studies that found that cattle performance did not differ between pastures managed with patch-burn grazing and pastures managed with a traditional range management practice. We acknowledge that input costs likely differed between PBG and TRAD pastures in our study, such that fire was only applied to TRAD pastures once during 3 years, whereas fire was applied in each of

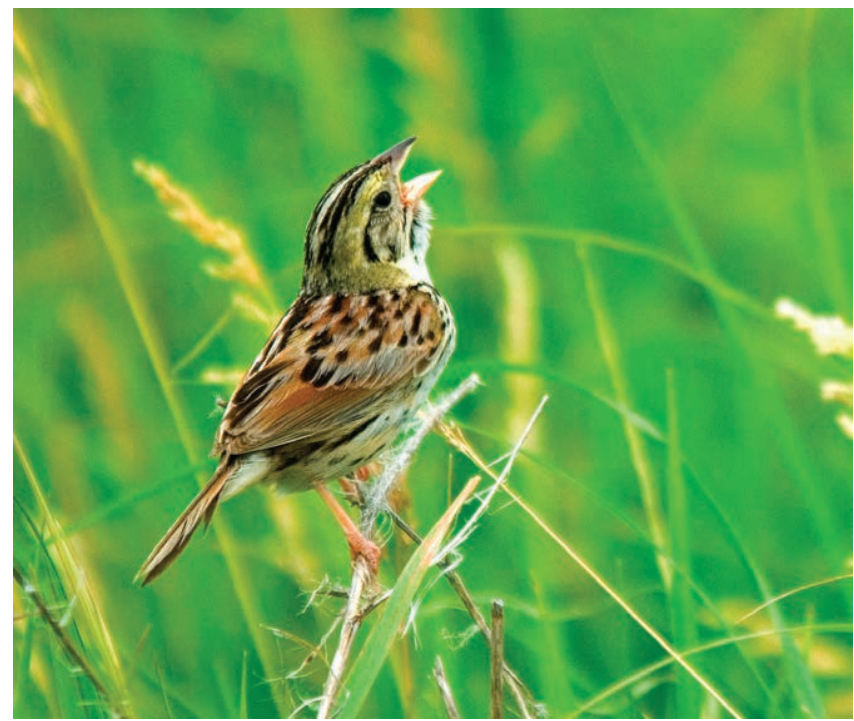

Figure 7. Henslow's sparrow, a grassland bird that has been found to benefit from patch-burn grazing in Oklahoma, was present at our southeastern Nebraska study sites, including some of our patch-burn grazing pastures. Photo by Chris Helzer/The Nature Conservancy.

3 years in the PBG pastures. Ideally, future patch-burn grazing research will include economic analyses that provide further insight on what managers might expect if they adopted patch-burn grazing as a management strategy. Nonetheless, in terms of cattle performance, patch-burn grazing appears to be a feasible range management practice in tallgrass prairie vegetation of southeastern Nebraska when compared to a traditional form of range management.

We conducted our research in a working landscape representing varied conditions encountered by livestock producers and land managers. This contrasts with research conducted in long-established study sites where the primary objective is successful completion of rigorous research and management activities are focused on the achievement of this objective. For instance, we were unable to maintain consistency in cattle breeds across all study sites because livestock were provided by local livestock producers, each of whom maintained herds comprised of breeds that met their particular needs and objectives outside of our study. Additionally, it would have been advantageous to measure cattle body mass at each of our study sites but this was not possible because of the broad geographic area across which our study sites were dispersed. Finally, a risk of conducting research across a broad range of conditions is that potential differences can be masked by "noise" resulting from a high amount of variability in the data. In spite of these shortcomings, our results likely approximate what livestock producers and land managers could expect to find if they implement patch-burn grazing in similar situations. Further studies of this type in other regions and vegetation types would further help livestock producers determine if patch-burn grazing is a management strategy they might adopt. An especially rewarding aspect of our research was that it involved land managers and livestock producers in the 
research process, providing them with insight on the methodology used in answering questions about management actions. Finally, our research also provided a unique opportunity to expose land managers and livestock producers to a management strategy that has been demonstrated to provide wildlife and biodiversity benefits that often aren't provided by traditional forms of range management.

\section{Acknowledgments}

We thank the many landowners whose pastures were utilized during the study. Their interest in and willingness to contribute to rangeland research is commendable. Additionally, Wildlife Area Managers Brad Seitz and Mike Remund of the Nebraska Game and Parks Commission were instrumental in the successful implementation and execution of the research on stateowned properties. Rick Schneider of the Nebraska Game and Parks Commission provided logistical support and grant administration assistance throughout the study. We also thank Jarren Kuipers and Kent Pfeiffer of the Nebraska Game and Parks Commission/Northern Prairies Land Trust for the crucial role they played in identifying landowners who were willing to participate in the study, and for continuing to work with all landowners, land managers, and researchers through the duration of the study to ensure successful completion of this research. Robert Gillen, David Engle, and anonymous reviewers provided helpful suggestions on prior versions of the manuscript.

\section{References}

1. Valentine, J. F. 2001. Grazing management. 2nd ed. San Diego, CA, USA: Academic Press. 659 p.

2. Holecheck, J. L., R. D. Pieper, and C. H. Herbel. 2004. Range management principles and practices. 5th ed. Upper Saddle River, NJ, USA: Pearson-Prentice-Hall. 607 p.

3. Weir,J. R., S. D. Fuhlendorf, D. M.Engle, T. G. Bidwell, D. C. Cummings, D. Elmore, R. F. Limb, J. D. Scasta, and S. L. WinTER. 2013. Patch burning: integrating fire and grazing to promote heterogeneity. Oklahoma Cooperative Extension Service circular E-998. Stillwater, OK, USA: Oklahoma State University. 26 p.

4. Derner, J. D., W. K. Lauenroth, P. Stapp, and D. J. AugusTINE. 2009. Livestock as ecosystem engineers for grassland bird habitat in the western Great Plains of North America. Rangeland Ecology \& Management 62:111-118.

5. Toоmbs, T. P., And M. G. Roberts. 2009. Are Natural Resources Conservation Service range management investments working at cross-purposes with wildlife habitat goals on western United States rangelands? Rangeland Ecology \& Management 62:351-355.

6. Fuhlendorf, S. D., D. M. Engle, R. D. Elmore, R. F. Limb, AND T. G. Bidwell. 2012. Conservation of pattern and process: developing an alternative paradigm of rangeland management. Rangeland Ecology \& Management 65:579-589.

7. Fuhlendorf, S. D., And D. M. Engle. 2004. Application of the fire-grazing interaction to restore a shifting mosaic on tallgrass prairie. Journal of Applied Ecology 41:604-614.
8. Limb, R. F., S. D. Fuhlendorf, D. M. Engle, J. R. Weir, R. D. Elmore, and T. G. Bidwell. 2011. Pyric-herbivory and cattle performance in grassland ecosystems. Rangeland Ecology E' Management 64:659-663.

9. Augustine, D. J., And J. D. Derner. 2013. Controls over the strength and timing of fire-grazer interactions in a semi-arid rangeland. Journal of Applied Ecology 51:242-250.

10. Peters, D. C., J. Belnap, J. A. Ludwig, S. L. Collins, J. Paruelo, M. T. Hoffman, and K. M. Havstad. 2012. How can science be general, yet specific? The conundrum of rangeland science in the 21st century. Rangeland Ecology \& Management 65:613-622.

11. Fuhlendorf, S. D., S. L. Winter, and B. Smith. 2013. Effects of patch burn grazing on biodiversity and cattle production in southeastern Nebraska: final report. Lincoln, NE, USA: Nebraska Game \& Parks Commision. 76 p.

12. Allred, B. W., S. D. Fuhlendorf, D. M. Engle, and R. D. Elmore. 2011. Ungulate preference for burned patches reveals strength of fire-grazing interaction. Ecology and Evolution 1:132-144.

13. Allred, B.W., S. D. Fuhlendorf, and R. G. Hamilton. 2011. The role of herbivores in Great Plains conservation: comparative ecology of bison and cattle. Ecosphere 2:art26. doi:10.1890/ ES10-00152.1.

14. Новвs, N. T., D. S. Schimel, C. E. Owensby, and D. S. Ojıma. 1991. Fire and grazing in the tallgrass prairie: contingent effects on nitrogen budgets. Ecology 72:1374-1382.

15. Holecheck, J. L., H. Gomez, F. Molinar, and D. Galt. 1999. Grazing studies: what we've learned. Rangelands 21:12-16.

16. Briske, D. D., J. D. Derner, J. R. Brown, S. D. Fuhlendorf, W. R. Teague, K. M. Havstad, R. L. Gillen, A. J. Ash, and W. D. Willms. 2008. Rotational grazing on rangelands: reconciliation of perception and experimental evidence. Rangeland Ecology \& Management 61:3-17.

17. Coppedge, B. R., S. D. Fuhlendorf, W. C. Harrell, and D. M. ENGLE. 2008. Avian community response to vegetation and structural features in grasslands managed with fire and grazing. Biological Conservation 141:1196-1203.

Authors are TWS Certified Wildlife Biologist ${ }^{\circledR}$, Winona, $M N$ 55987, USA, stephen.winter@okstate.edu (Winter); Regents Professor and Sarkeys Distinguished Professor, Dept of Natural Resource Ecology and Management, Oklahoma State University, Stillwater, OK 74078, USA (Fublendorf); and Animal Science Instructor, Southeast Community College, Beatrice, NE 68310, USA (Goes). At the time of research, Winter was a Senior Research Assistant, Dept of Natural Resource Ecology and Management, Oklahoma State University, Stillwater, OK 74078, USA. Research was funded in part by the Nebraska Game and Parks Commission, the US Fish and Wildlife Service State Wildlife Grants Program, and the Nebraska Environmental Trust Fund. 